\title{
JOURNAL OF ENERGY SYSTEMS
}

Volume 1, Issue 1

DOI: $10.30521 /$ jes.351269

\section{Control of dual stator induction generator integrated in wind energy conversion system}

\author{
Meryem Benakcha \\ Electrical Engineering Laboratory LGE, M'sila University BP 166, Algeria, benakcha.meryem@gmail.com \\ Leila Benalia \\ Electrical Engineering Laboratory LGE, M’sila University BP 166, Algeria, leila_bena@yahoo.fr \\ Fatima Ameur \\ Semi-Conductors \& Functional Materials Laboratory, Laghouat University BP 73G, Algeria, \\ ameurfatima1@gmail.com \\ Djamel Eddine Tourqui \\ L2GEG Research Laboratory, Tiaret University BP 78, Algeria, djamel@gmail.com
}

Arrived: 26.06.2017 Accepted: 23.08.2017 Published: 04.09.2017

\begin{abstract}
This paper deals with the modeling and the control of a dual stator induction generator (DSIG) integrated into a wind energy conversion system with a variable speed wind turbine. DSIG is increasingly used because of its advantages in better reliability and supply division. It consists of two fixed three-phase stator windings displaced with an electrical angle $\alpha$. To minimize the harmonic distortion (THD), the objective of this work is to study the influence of the angle between these two stator windings on the grid generated current quality. To improve the performance of the system, the proposed control is demonstrated through an illustrative simulation.
\end{abstract}

Keywords:

Dual stator induction generator, Variable speed wind turbine, Field oriented control, Maximum power point tracking (MPPT). \section{Benakcha, L. Benalia, F. Ameur, D.J. Tourqui, Control of dual stator induction generator
Cite this paper as: $\quad$ integrated in wind energy conversion system, Journal of Energy Systems 2017, 1(1):21-31, DOI: $10.30521 /$ jes.351269}

C 2017 Published by JES peer-review scientific journal at DergiPark (www.dergipark.gov.tr/jes)

\begin{tabular}{|c|c|c|c|}
\hline Nomenclature & & & \\
\hline $\mathrm{G}$ & Gearbox & $\omega_{\mathrm{s}}$ & Synchronous reference frame Speed \\
\hline $\mathrm{P}$ & Number of pole pairs & $\omega_{\mathrm{r}}$ & Rotor electrical angular speed \\
\hline $\mathrm{T}_{\mathrm{g}}$ & Generator Torque & $\Omega_{\mathrm{mec}}$ & Mechanical speed of the DSIG \\
\hline $\mathrm{R}_{\mathrm{s} 1}, \mathrm{R}_{\mathrm{s} 2}$ & Stator resistance & $\mathrm{v}_{\mathrm{ds} 1} \mathrm{v}_{\mathrm{qs} 1} \mathrm{v}_{\mathrm{ds} 2} \mathrm{v}_{\mathrm{qs} 2}$ & d-q stator voltages \\
\hline $\mathrm{L}_{\mathrm{s} 1}, \mathrm{~L}_{\mathrm{s} 2}$ & Stator inductance & $\mathrm{v}_{\mathrm{dr}} \mathrm{v}_{\mathrm{qr}}$ & $\mathrm{d}-\mathrm{q}$ rotor voltages \\
\hline $\mathrm{L}_{\mathrm{m}}$ & Magnetizing inductance & $\mathrm{l}_{\mathrm{ds} 1} \mathrm{l}_{\mathrm{qs} 1} \mathrm{l}_{\mathrm{ds} 2} \mathrm{l}_{\mathrm{qs} 2}$ & d-q stator currents \\
\hline $\mathrm{R}_{\mathrm{r}}$ & Rotor resistance & $\mathrm{l}_{\mathrm{dr}} \mathrm{l}_{\mathrm{gr}}$ & $\mathrm{d}-\mathrm{q}$ rotor currents \\
\hline $\mathrm{L}_{\mathrm{r}}$ & Rotor inductance & $\mathrm{L}_{\mathrm{t}}$ & Filter inductance \\
\hline $\mathrm{J}$ & Inertia & $\mathrm{R}_{\mathrm{r}}$ & Filter resistance \\
\hline $\begin{array}{r}f \\
\omega_{g l}\end{array}$ & $\begin{array}{l}\text { Viscous coefficient } \\
\text { Sliding speed }\end{array}$ & $\mathrm{C}$ & Capacitance of the DC link voltage \\
\hline
\end{tabular}




\section{INTRODUCTION}

Wind power is a clean source of energy. It is a "renewable" energy, non-degraded, geographically widespread and mainly seasonal correlation. Moreover, it is an energy that produces no atmospheric emissions or radioactive waste $[1,2]$. However, it is random in time and its capture still quite complex. At the beginning, it was exploited in mechanical applications. Thereafter, it has been used to produce electricity. The wind turbine manufacturing technology has been improved during the $1^{\text {st }}$ and $2^{\text {nd }}$ world wars. The oil crisis of 1974 revived again the studies on the wind turbines. Since the years 1990, the improvement of the technology of the wind turbines made it possible to build aero generators of more than $5 \mathrm{MW}$ [3].

Several technologies are used to capture the energy of the wind (vertical and horizontal axis turbines) and the capture structures are becoming more efficient [4]. Furthermore, the speed of the wind is very important. The integration of wind energy systems requires the reduction of operating costs and maintenance, as well as increasing the power captured from the wind [5]. Many devices exist and, mostly, they use synchronous and asynchronous machines. The control strategies of these machines and their possible network connection interfaces must be able to capture maximum energy over a wider range of variation of wind speeds, to improve the profitability of wind turbines [6]. The studied system here consists of an aero generator three-bladed, with horizontal axis, connected to the network by the dual stator induction generator (DSIG). This type of multiphase machines has some advantages compared to other types of induction machines, such as power segmentation, minimizing torque ripples, reducing the rotor harmonic currents and the use of this machine in wind projects of which powers are of a few MW. It has two fixed three-phase stator windings displaced with an electrical angle $\alpha$ fed by two voltage source inverters [7-9]. By simulating the entire wind conversion chain with different electrical angles, the objective of this work is to define the optimal angle which reduces the total harmonic distortion (THD). In what follows, we perform a quantitative analysis that will give the necessary conclusions about the effect that can have such angle on the reduction of harmonics. A high performance control device requires in general a good response in regulation and must be not very sensitive to the variations of operating conditions and system parameter [10]. Techniques of conventional control of PI type cover a broad range in the industrial applications. These techniques present a simplicity of implementation interest and a facility of the regulators gains synthesis [11].

The mathematical model of the turbine and the DSIG, the vector control sharing of powers between the wind system and the network will be studied and detailed. The simulation model was developed in a Matlab/Simulink environment.

\section{WIND POWER CONVERSION MODELLING}

Wind power conversion chain studied includes, besides the DSIG, the inverters 1,2 the DC link voltage, the inverter 3 and the connexion to the network through a filter. The inverters 1 and 2 are used to control the speed and flux of the generator. This control is based on the MPPT algorithm. The inverter 3 controls the DC link voltage, the active and the reactive powers exchanged with the network and establishes current to the proper frequency by PI controllers. Fig.1 shows the synoptic scheme of the studied system. Each function of this control device will be detailed.

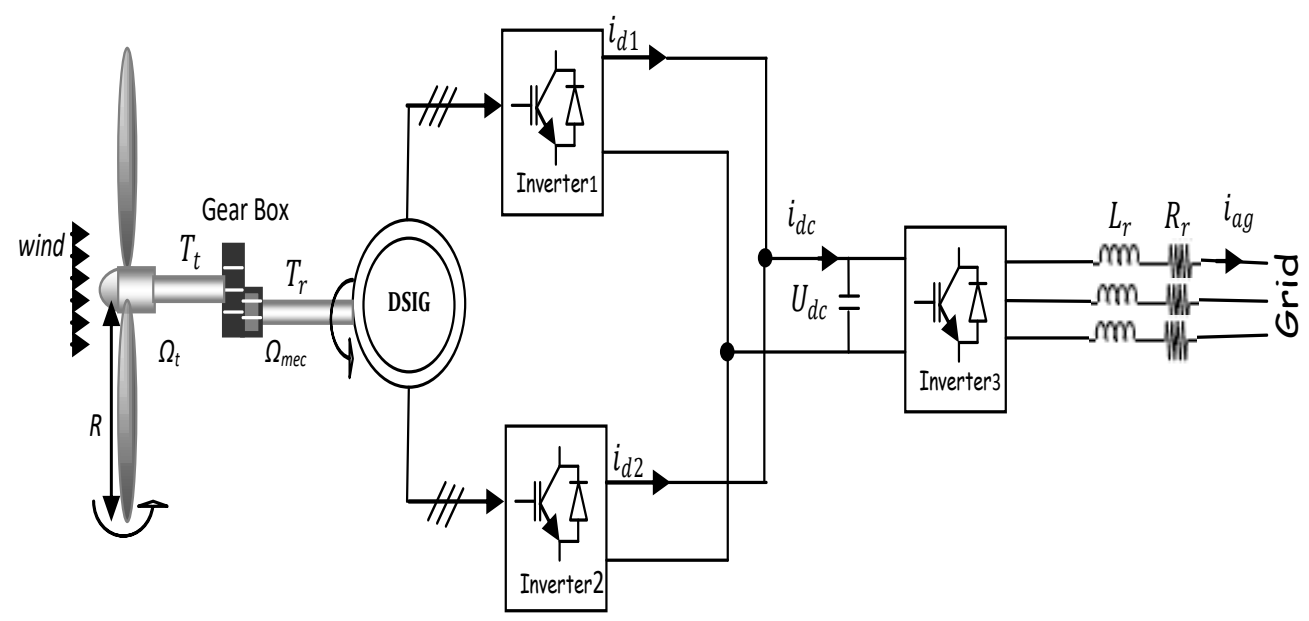

Figure 1. Block diagram of the wind power system based on DSIG 


\section{WIND TURBINE and GEARBOX MODELLING}

The transmitted power, $P_{t}$, captured by the wind turbine, is given by expression $(1)[12,13]$.

$$
P_{t}=0.5 C_{p}(\lambda) \rho S V^{3}
$$

Where $\mathrm{C}_{\mathrm{p}}$ is the power coefficient, $\mathrm{S}$ the surface swept by the blades, $\rho$ the air density and $\mathrm{V}$ the wind velocity. The torque of the turbine is the ratio of the transmitted power to the shaft speed, $\Omega_{t}$. It is given by:

$$
T_{t}=\frac{P_{t}}{\Omega_{t}}
$$

The gearbox adapts the generator to the turbine. The generator torque $\mathrm{T}_{\mathrm{g}}$ and the speed $\Omega_{\mathrm{t}}$ are given by:

$$
T_{g}=\frac{T_{t}}{G} \quad, \Omega_{t}=\frac{\Omega_{m e c}}{G}
$$

The mechanical equation can be expressed as:

$$
J p \Omega_{m e c}=T_{g}-T_{e m}-f \Omega_{m e c}
$$

The power coefficient $C_{p}$ is the aerodynamic efficiency of a wind turbine and its evolution is specific to each turbine and wind speed. It depends on the blade pitch angle $\beta$ and the speed ratio $\lambda$ which is expressed by [10]:

$$
\lambda=\frac{R \Omega_{t}}{V}
$$

Where $\mathrm{R}$ is the blade radius.

$$
C_{p}=\left[0.73\left(\frac{151}{\lambda^{\prime}}\right)-0.002 \beta-13.2\right] \exp \left(\frac{-18.4}{\lambda^{\prime}}\right)
$$

With: $\lambda^{\prime}=\left[1 /(\lambda+0.08 \beta)-0.035 /\left(\beta^{3}+1\right)\right]^{-1}$

For the value $\beta=0$, the graph of $\mathrm{p}_{\mathrm{p}}(\lambda)$, given in Fig. 2, is plotted using expression (6). The conversion device extracts a power less than the theoretically recoverable power due to non-zero speed of air masses upstream of the turbine. This presents a theoretical limit called the Betz limit which corresponds to a $C_{\text {pmax }}[10,14]$.

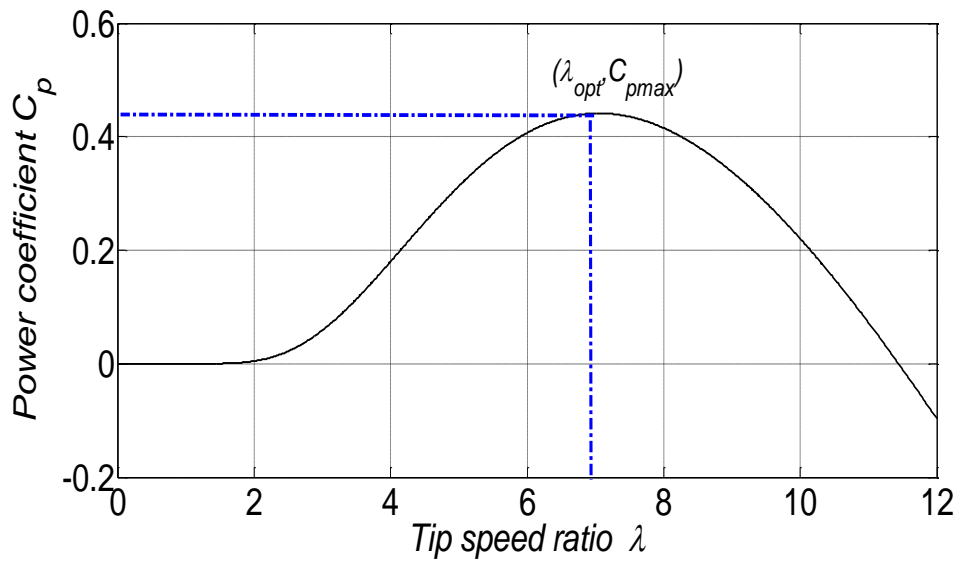

Figure 2. The graph of Cp function $\lambda$

The maximum power point tracking (MPPT) algorithm permits to maximize the electric power extracted from the wind energy [15]. The tip speed ratio should be kept around its optimal value, $\lambda_{\text {opt }}$. The reference speed $\Omega_{m e c}^{*}$ can be written as: 


$$
\Omega_{m e c}^{*}=\left(\frac{R \lambda_{\text {opt }}}{V}\right) \cdot G
$$

The block diagram of the turbine model with the control of the speed is represented in Fig. 3.

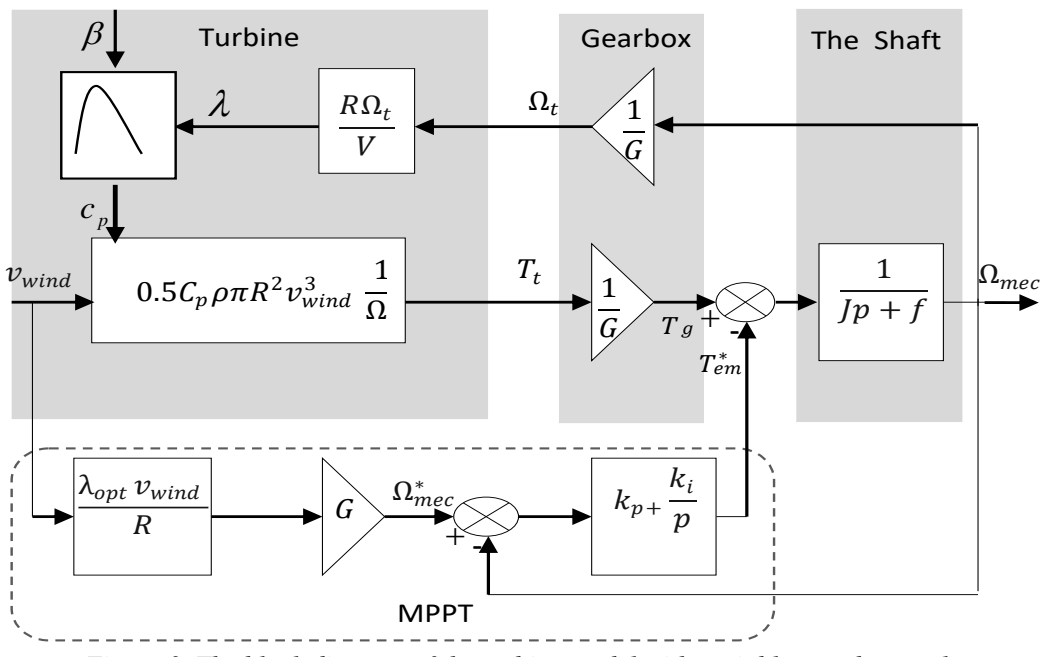

Figure 3. The block diagram of the turbine model with variable speed control

\section{MODELLING of the DSGI}

The dual stator induction generator (DSIG) consists of a mobile rotor winding and two fixed three-phase stator windings displaced with an electrical angle $\alpha$. The windings axes of each star are displaced with an electrical angle $2 \pi / 3$ and fed by a balanced voltages system, creating a slipping magnetic field in the air-gap. The rotor is a squirrel cage consisting of conducting bars short-circuited by a conductive ring at each end Fig. 4 shows schematically the windings of the DSIG. The $\theta_{r}$ and $\left(\theta_{r}-\alpha\right)$ angles indicate respectively the rotor position of $a_{s 1}$ phase (star 1) and $a_{s 2}$ phase (star 2). The quantities relating to the two stars (1 and 2) will be denoted by s1 and s2 respectively $[7,8,16]$.

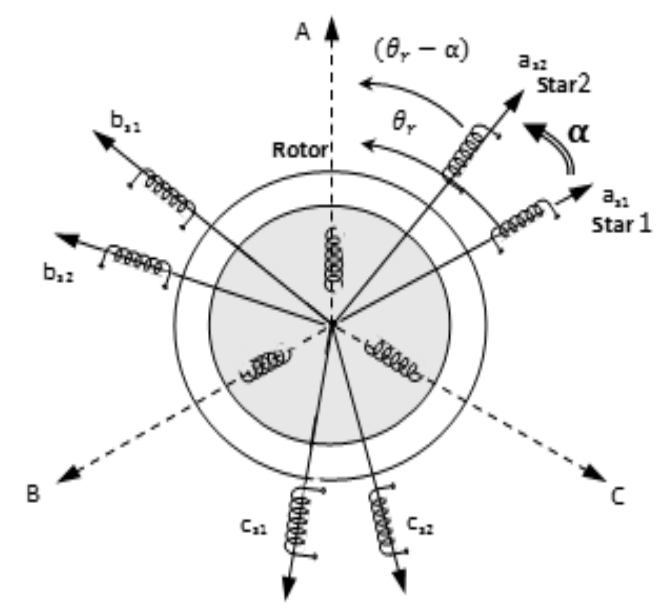

Figure 4. Schematic of dual stator induction generator

The electrical equations in matrix form for the star 1, the star 2 and the rotor are given respectively by:

$$
\begin{gathered}
{\left[v_{s 1}\right]=\left[R_{s 1}\right]\left[\left[i_{s 1}\right]+\frac{d}{d t}\left[\varphi_{s 1}\right]\right.} \\
{\left[v_{s 2}\right]=\left[R_{s 2}\right]\left[\left[i_{s 2}\right]+\frac{d}{d t}\left[\varphi_{s 2}\right]\right.} \\
{\left[v_{r}\right]=\left[R_{r}\right]\left[\left[i_{r}\right]+\frac{d}{d t}\left[\varphi_{r}\right]\right.}
\end{gathered}
$$

With: $\left[v_{s 1}\right]=\left[\begin{array}{l}v_{a s 1} \\ v_{b s 1} \\ v_{c s 1}\end{array}\right] ;\left[v_{s 2}\right]=\left[\begin{array}{l}v_{a s 2} \\ v_{b s 2} \\ v_{c s 2}\end{array}\right] ;\left[v_{r}\right]=\left[\begin{array}{c}v_{a r} \\ v_{b r} \\ v_{c r}\end{array}\right]$ 
The flux expressions (for star1, star 2 and the rotor) in function of the currents are given by:

$$
\left[\begin{array}{c}
\varphi_{s 1} \\
\varphi_{s 2} \\
\varphi_{r}
\end{array}\right]=\left[\begin{array}{lll}
{\left[L_{s 1, s 1}\right]} & {\left[L_{s 1, s 2}\right]} & {\left[L_{s 1, r}\right]} \\
{\left[L_{s 2, s 1}\right]} & {\left[L_{s 2, s 2}\right]} & {\left[L_{s 2, r}\right]} \\
{\left[L_{r, s 1}\right]} & {\left[L_{r, s 2}\right]} & {\left[L_{r, r}\right]}
\end{array}\right]\left[\begin{array}{c}
i_{s 1} \\
i_{s 1} \\
i_{r}
\end{array}\right]
$$

Where:

$$
\begin{aligned}
& {\left[L_{s 1, s 2}\right]=\left[\begin{array}{ccc}
L_{m s} \cos (\alpha) & L_{m s} \cos \left(\alpha+\frac{2 \pi}{3}\right) & L_{m s} \cos \left(\alpha+\frac{4 \pi}{3}\right) \\
L_{m s} \cos \left(\alpha-\frac{2 \pi}{3}\right) & L_{m s} \cos (\alpha) & L_{m s} \cos \left(\alpha+\frac{2 \pi}{3}\right) \\
L_{m s} \cos \left(\alpha-\frac{4 \pi}{3}\right) & L_{m s} \cos \left(\alpha-\frac{2 \pi}{3}\right) & L_{m s} \cos (\alpha)
\end{array}\right]} \\
& {\left[L_{s 2, r}\right]=\left[\begin{array}{ccc}
L_{s r} \cos \left(\theta_{r}-\alpha\right) & L_{s r} \cos \left(\theta_{r}-\alpha+\frac{2 \pi}{3}\right) & L_{s r} \cos \left(\theta_{r}-\alpha+\frac{4 \pi}{3}\right) \\
L_{s r} \cos \left(\theta_{r}-\alpha-\frac{2 \pi}{3}\right) & L_{s r} \cos \left(\theta_{r}-\alpha\right) & L_{s r} \cos \left(\theta_{r}-\alpha+\frac{2 \pi}{3}\right) \\
L_{s r} \cos \left(\theta_{r}-\alpha-\frac{4 \pi}{3}\right) & L_{s r} \cos \left(\theta_{r}-\alpha-\frac{2 \pi}{3}\right) & L_{s r} \cos \left(\theta_{r}-\alpha\right)
\end{array}\right]}
\end{aligned}
$$

The mathematical model of the DSIG is derived from the PARK theory in order to simplify the differential equations as shown in Fig.5.

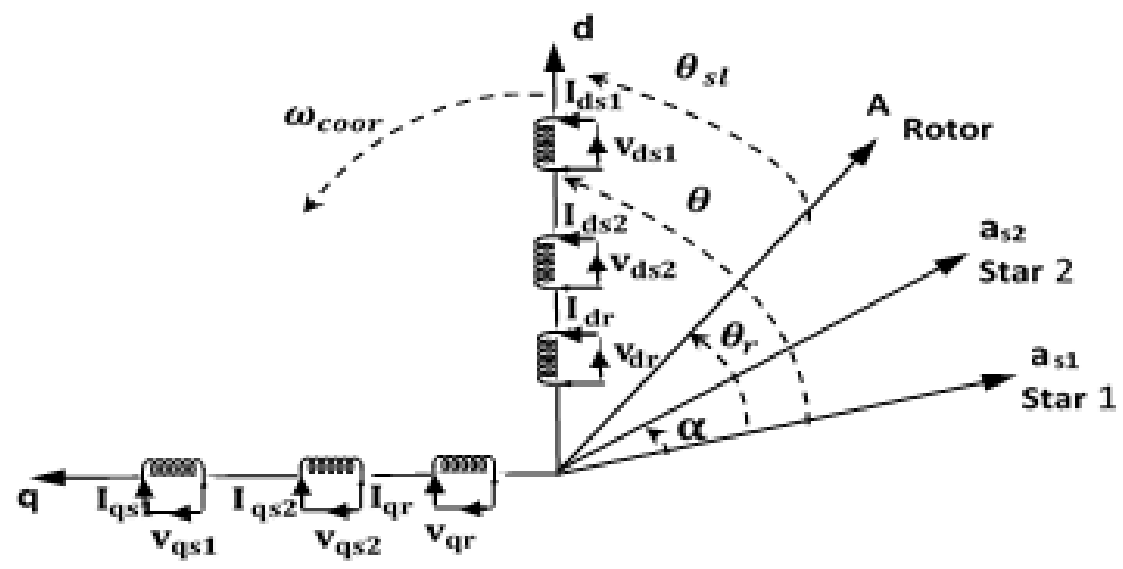

Figure 5. Representation of the DSIG model along the axes $(d, q)$

$$
[\dot{I}]=[L]^{-1}\left\{[B][U]-\omega_{g l}[C][I]-[D][I]\right\}
$$

Where:

$$
\begin{aligned}
& \omega_{g l}=\omega_{s}-\omega_{r}, \omega_{r}=p * \Omega_{m e c} \\
& {[U]=\left[\begin{array}{lllll}
v_{d s 1} v_{q s 1} v_{d s 2} v_{q s 2} & v_{d r} & v_{q r}
\end{array}\right]^{t}} \\
& {[I]=\left[\begin{array}{llllll}
\iota_{d s 1} l_{q s 1} & \iota_{d s 2} & \iota_{q s 2} & \iota_{d r} & \iota_{q r}
\end{array}\right]^{t}} \\
& {[\dot{I}]=\frac{d}{d t}[I]} \\
& {[B]=\operatorname{diag}\left[\begin{array}{cccccc}
1 & 1 & 1 & 1 & 0 & 0
\end{array}\right]} \\
& {[C]=\left[\begin{array}{cccccc}
0 & 0 & 0 & 0 & 0 & 0 \\
0 & 0 & 0 & 0 & 0 & 0 \\
0 & 0 & 0 & 0 & 0 & 0 \\
0 & 0 & 0 & 0 & 0 & 0 \\
0 & -L_{m} & 0 & -L_{m} & 0 & -\left(L_{r}+L_{m}\right) \\
L_{m} & 0 & L_{m} & 0 & L_{r}+L_{m} & 0
\end{array}\right]}
\end{aligned}
$$




$$
\begin{aligned}
{[L] } & =\left[\begin{array}{cccccc}
\left(L_{s 1}+L_{m}\right) & 0 & L_{m} & 0 & L_{m} & 0 \\
0 & \left(L_{s 1}+L_{m}\right) & 0 & L_{m} & 0 & L_{m} \\
L_{m} & 0 & \left(L_{s 2}+L_{m}\right) & 0 & L_{m} & 0 \\
0 & L_{m} & 0 & \left(L_{s 2}+L_{m}\right) & 0 & L_{m} \\
L_{m} & 0 & L_{m} & 0 & \left(L_{r}+L_{m}\right) & 0 \\
0 & L_{m} & 0 & L_{m} & 0 & \left(L_{r}+L_{m}\right)
\end{array}\right] \\
{[D] } & =\left[\begin{array}{cccccc}
R_{s 1} & -\omega_{s}\left(L_{s 1}+L_{m}\right) & 0 & -\omega_{s} L_{m} & 0 & -\omega_{s} L_{m} \\
\omega_{\boldsymbol{s}}\left(L_{s 1}+L_{m}\right) & R_{s 1} & \omega_{s} L_{m} & 0 & \omega_{s} L_{m} & 0 \\
0 & -\omega_{s} L_{m} & R_{s 2} & -\omega_{s}\left(L_{s 2}+L_{m}\right) & 0 & -\omega_{s} L_{m} \\
\omega_{s} L_{m} & 0 & \omega_{s}\left(L_{s 2}+L_{m}\right) & R_{s 2} & \omega_{s} L_{m} & 0 \\
0 & 0 & 0 & 0 & R_{r} & 0 \\
0 & 0 & 0 & 0 & 0 & R_{r}
\end{array}\right]
\end{aligned}
$$

The electromagnetic torque is expressed by:

$$
T_{e m}=P \frac{L_{m}}{\left(L_{m}+L_{r}\right)}\left[\left(\iota_{q s 1}+\iota_{q s 2}\right) \varphi_{d r}-\left(\iota_{d s 1}+\iota_{d s 2}\right) \varphi_{q r}\right]
$$

The active and reactive power are described by:

$$
\left\{\begin{array}{l}
P_{s}=v_{d s 1} l_{d s 1}+v_{q s 1} l_{q s 1}+v_{d s 2} l_{d s 2}+v_{q s 2} l_{q s 2} \\
Q_{s}=v_{q s 1} l_{d s 1}-v_{d s 1} l_{q s 1}+v_{q s 2} l_{d s 2}-v_{d s 2} l_{q s 2}
\end{array}\right.
$$

\section{FIELD ORIENTED CONTROL of DSIG}

The field-oriented control (FOC) achieves a natural decoupling control of flux and the torque such as in the case of a separately excited DC machine. The control laws of the FOC are derived from the DSIG equations by the Park transformation related to the rotating field $(\mathrm{d}, \mathrm{q})$ and the rotor flux orientation. This is obtained by letting the rotor flux $\varphi_{\mathrm{dr}}$ component and the vector $\mathrm{i}_{\mathrm{dr}}$ aligned in $\mathrm{d}$-axis direction. The electromagnetic torque and the component vector $\mathrm{i}_{\mathrm{qr}}$ are kept in q-axis direction. The flux $\varphi_{\mathrm{qr}}$ is kept equal to zero [17].

Expressions of the electromagnetic torque and slip speed references are respectively $[9,18]$ :

$$
\begin{gathered}
T_{e m}^{*}=P \frac{L_{m}}{\left(L_{m}+L_{r}\right)}\left(\iota_{q s 1}^{*}+\iota_{q s 2}^{*}\right) \varphi_{r}^{*} \\
\omega_{s l}^{*}=\frac{r_{r} L_{m}}{L_{m}+L_{r}} \frac{\left(\iota_{q s 1}^{*}+l_{q s 2}^{*}\right)}{\varphi_{r}^{*}}
\end{gathered}
$$

With: $\iota_{d s 1}^{*}+\iota_{d s 2}^{*}=\frac{\varphi_{r}^{*}}{L_{m}}$

To compensate the error introduced during the decoupling of the torque and the flux, the references stator voltages at constant flux are expressed by:

$$
\left\{\begin{array}{l}
v_{d s 1}^{*}=v_{d f s 1}-v_{d s 1 c} \\
v_{q s 1}^{*}=v_{q f s 1}+v_{q s 1 c} \\
v_{d s 2}^{*}=v_{d f s 2}-v_{d s 2 c} \\
v_{q s 2}^{*}=v_{q f s 2}+v_{q s 2 c}
\end{array}\right.
$$

Where:

$$
\left\{\begin{array}{c}
v_{d s 1 c}=\omega_{s}^{*}\left(L_{s 1} l_{q s 1}+\tau_{r} \varphi_{d r}^{*} \omega_{s l}^{*}\right) \\
v_{q s 1 c}=\omega_{s}^{*}\left(L_{s 1} l_{d s 1}+\varphi_{d r}^{*}\right) \\
v_{d s 2 c}=\omega_{s}^{*}\left(L_{s 2} l_{q s 2}+\tau_{r} \varphi_{d r}^{*} \omega_{s l}^{*}\right) \\
v_{q s 2 c}=\omega_{s}^{*}\left(L_{s 2} \iota_{d s 2}+\varphi_{d r}^{*}\right)
\end{array}\right.
$$


The control block diagram is represented by Fig.6.

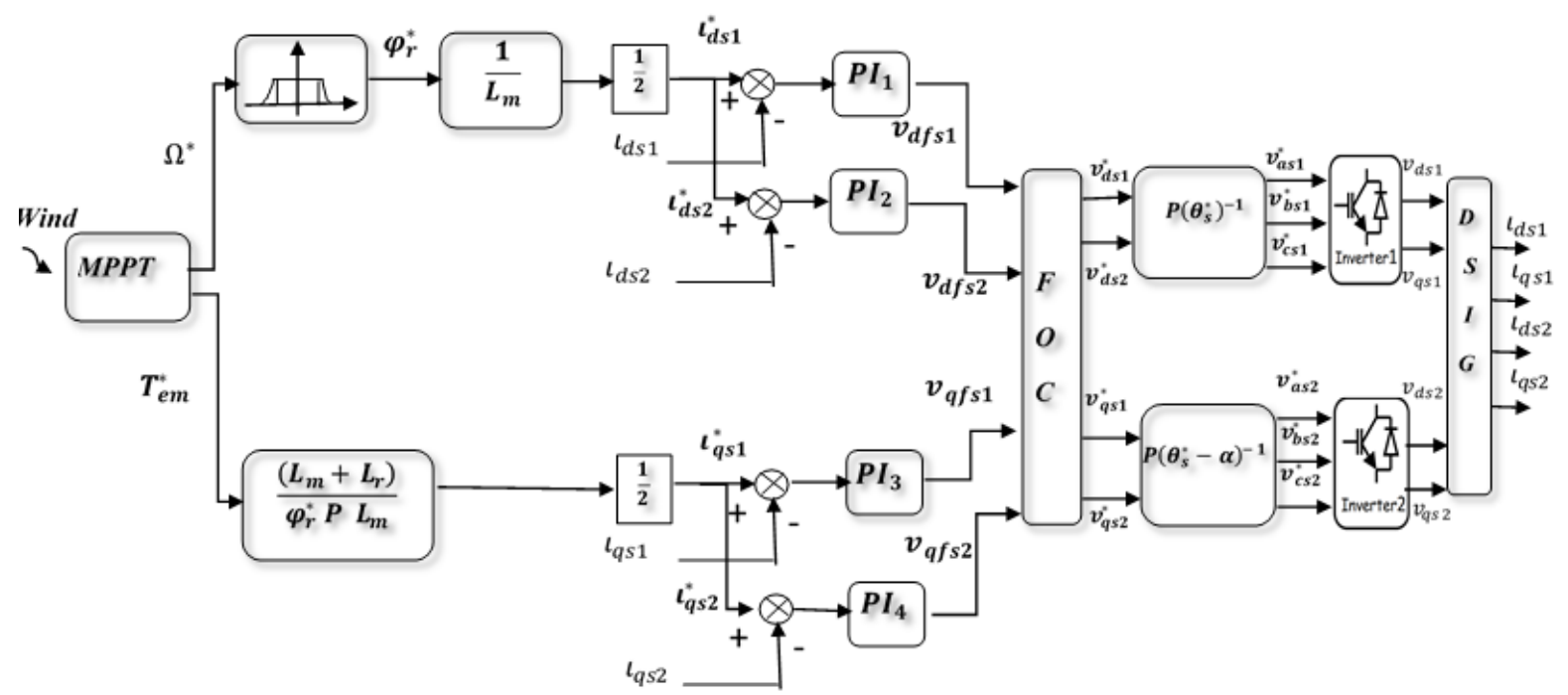

Figure 6. The block control diagram

\section{GRID-SIDE POWER CONTROL}

Mathematical modelling of the DC link system studied is as follows:

$$
\frac{d U_{d c}}{d t}=\frac{1}{C}\left(\iota_{d c}-\iota_{m}\right)
$$

Where:

$$
\iota_{d c}=\iota_{d 1}+\iota_{d 2}
$$

The topology of the inverter 3 (Fig.1) permits to generate and to call a current from the network. Its objective is to maintain the voltage of the DC link constant whatever the amplitude and the direction of transition from the power. This later is controlled so as to control the currents forwarding by the filter $\left(\mathrm{R}_{\mathrm{r}}, \mathrm{L}_{\mathfrak{r}}\right)$. So, a vector control in the Park model is achieved using a synchronized reference with the voltages of the low-side network. From the measurement of the voltage of the DC link, the inverter is controlled in order to impose the references to the simple voltages $\left(\mathrm{v}_{\mathrm{d}_{-} \text {inv }}, \mathrm{v}_{\mathrm{q}_{-} \text {inv }}\right)$. By tuning of these last, the Park components of the currents $\left(\mathrm{l}_{\mathrm{dg}}, \mathrm{l}_{\mathrm{qg}}\right)$ are controlled by PI correctors with compensation [19, 20].

The reference voltages expressed in $\mathrm{d}-\mathrm{q}$ frame are given by:

$$
\left\{\begin{array}{l}
v_{d \_i n v}^{*}=v_{d g}^{*}+v_{d g}-\omega_{s} L_{t} \iota_{q g} \\
v_{q_{-} i n v}^{*}=v_{q g}^{*}+v_{q g}+\omega_{s} L_{t} \iota_{d g}
\end{array}\right.
$$

Where:

$\left\{\begin{array}{l}\mathrm{v}_{\mathrm{dg}}^{*}=\operatorname{PI}(\mathrm{s})\left(\mathrm{\iota}_{\mathrm{dg}}^{*}-\mathrm{\iota}_{\mathrm{dg}}\right) \\ \mathrm{v}_{\mathrm{qg}}^{*}=\operatorname{PI}(\mathrm{s})\left(\mathrm{\iota}_{\mathrm{qg}}^{*}-\mathrm{\iota}_{\mathrm{qg}}\right)\end{array}\right.$

The network currents are expressed as:

$$
\left\{\begin{array}{l}
\iota_{d g}=\frac{1}{\left(R_{t}+L_{t} s\right)}\left(v_{d_{-} i n v}-v_{d g}-L_{t} \omega_{s} \iota_{q g}\right) \\
\iota_{q g}=\frac{1}{\left(R_{t}+L_{t} s\right)}\left(v_{q_{-} i n v}-v_{q g}+L_{t} \omega_{s} \iota_{d g}\right)
\end{array}\right.
$$


The grid reference reactive power is imposed, $\mathrm{Q}_{\mathrm{g}}^{*}=0$, in order to achieve the unity power factor in electrical supply network side.

The grid reference active power is:

$$
P_{g}^{*}=U_{d c} \iota_{d c}-U_{d c} \iota_{d c}^{*}
$$

Where the tuning of the DC link is carried out by a regulation loop, using a PI corrector, which generates the capacitive current reference $\left(\mathrm{l}_{\mathrm{dc}}^{*}\right)$ in the capacitor:

$$
\iota_{d c}^{*}=P I(s)\left(U_{d c}^{*}-U_{d c}\right)
$$

Network reference currents expressions can be represented by:

$$
\left\{\begin{array}{l}
\iota_{d g}^{*}=\frac{P_{g}^{*} v_{d g}+Q_{g}^{*} v_{q g}}{v_{d g}^{2}+v_{q g}^{2}} \\
\iota_{q g}^{*}=\frac{P_{g}^{*} v_{q g}-Q_{g}^{*} v_{d g}}{v_{d g}^{2}+v_{q g}^{2}}
\end{array}\right.
$$

\section{SIMULATION RESULTS and DISCUSSION}

The simulation results of the control system, which already presented, are implemented using Matlab / Simulink software for the wind speed profile depicted in Fig.7.The DSIG used in this work rated at 1.5 MW, whose nominal parameters are indicated in appendix, is simulated by choosing $\alpha=30^{\circ}$.

It is clear from Fig. 8 that the rotation speed follows perfectly its reference, which varies depending on the imposed wind profile. The waveform of the electromagnetic torque generator follows its reference resulting from the MPPT algorithm as shown in Fig.9. The decoupling of the direct and quadratic rotor fluxes of the DSIG is illustrated in Fig.10. We can see that the quadratic rotor flux has zero value, as the oriented control field requires.

The evolution of DSIG stator currents in the first phase of each star at all simulation time is shown in Fig. 11a and between 8 and 8.06s is shown in Fig 11.b. These currents are sinusoidal, displaced with $\alpha=30^{\circ}$.

The DC link voltage is constant and follows its set level 1130 V Fig.12. It can be seen from Fig.13 that the active and reactive grid powers follow in an acceptable way in accordance to their references at all simulation time. In order to get a unit power-factor in network side the reactive power reference $\mathrm{Q}_{\mathrm{g}}^{*}$ is fixed at zero value. The voltage and current grid and their zoom are given respectively in (fig.14a and b) respectively. It is clear that the current has sinusoidal form and opposite phase with respect to the voltage meaning that power flows from the aero generator to the grid. Fig.15 in turn, gives the spectrum THD (total harmonic distortion) of the grid current Ig1. This THD is defined as the ratio of total effective value of harmonics (their quadratic sum) to the RMS value of the fundamental component. We will analyze a sequence of time between $[1.4 \mathrm{~s}, 1.42 \mathrm{~s}]$ which corresponds to the period of the generated current.

As we see, the harmonics appearing in the grid current are minimized.Table1 presents the THD for different angles $\alpha$. We can notice that at $\alpha=30^{\circ}$ the THD $=3.37 \%$ which is reduced compared with other angles.

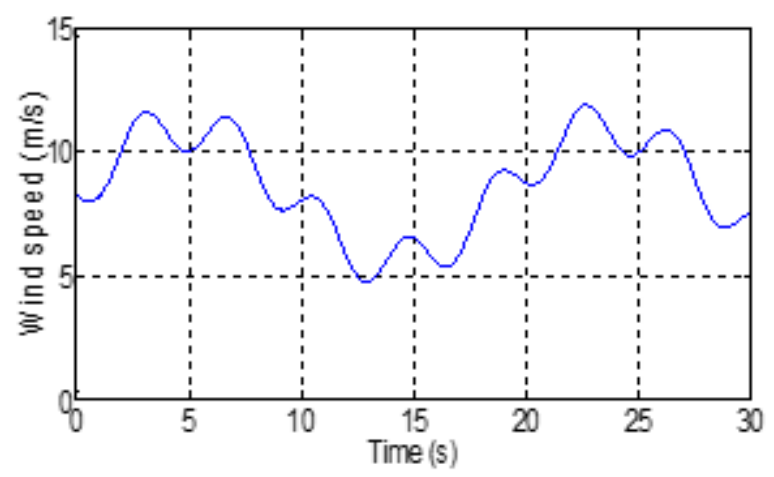

Figure 7. Profile of wind speed

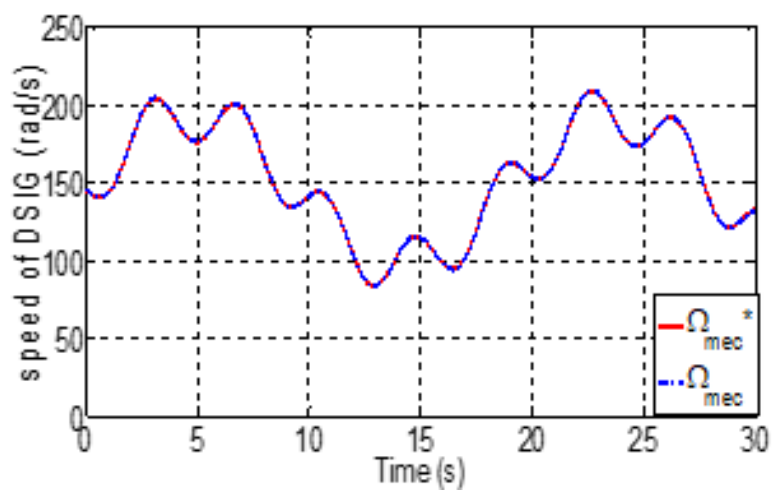

Figure 8. DSIG speed and its reference 


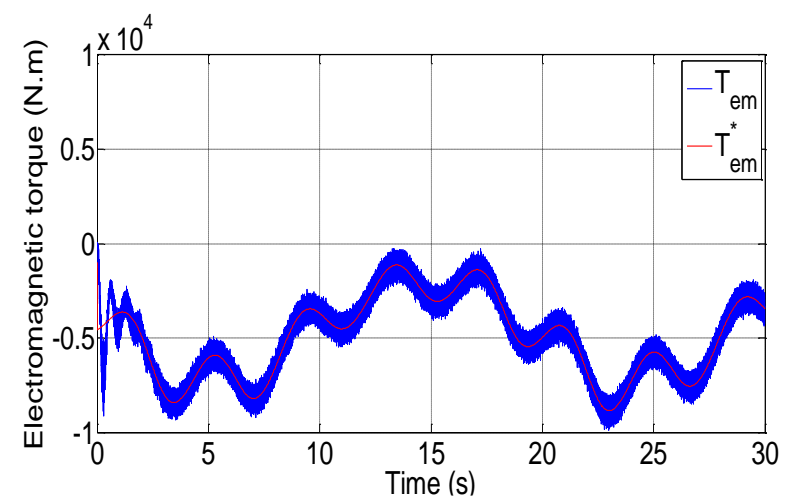

Figure 9. DSIG Torque and its reference



Figure 11.a Stator current of the star1 and star2

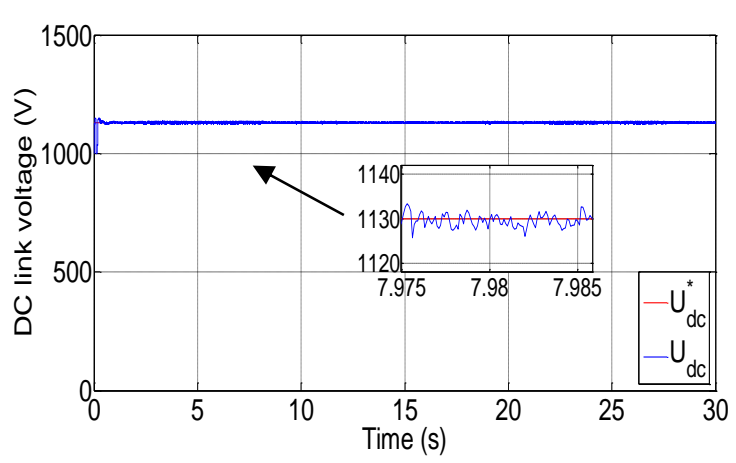

Figure 12. DC link voltage

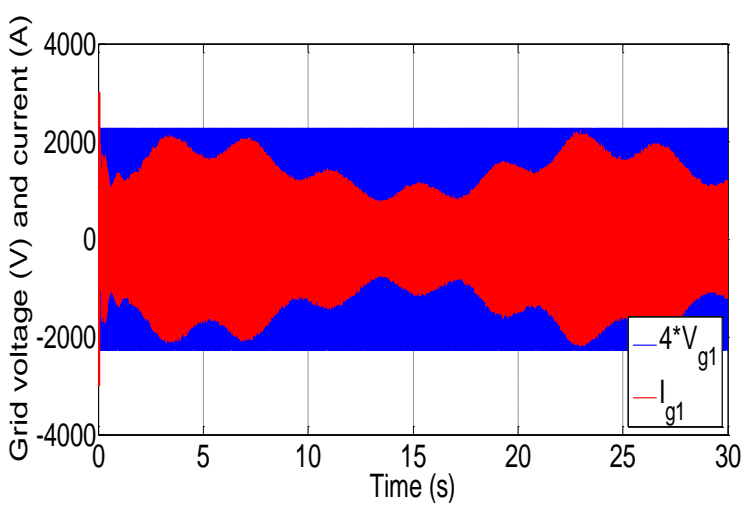

Figure 14.a. Grid voltage and current

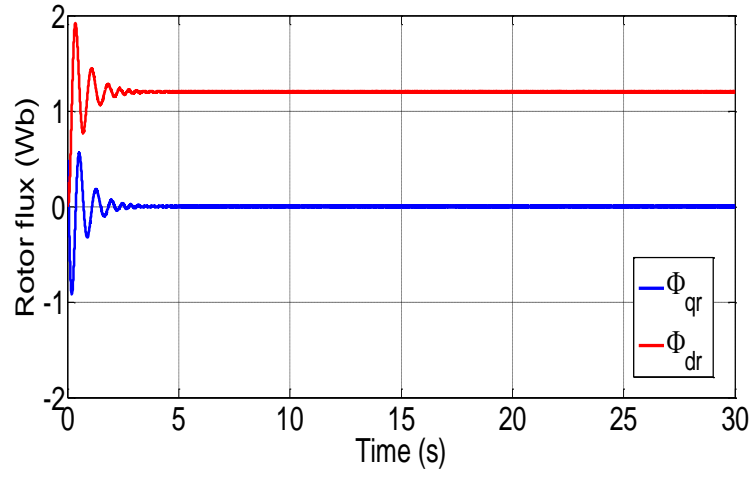

Figure 10. Direct and quadratic rotor flux

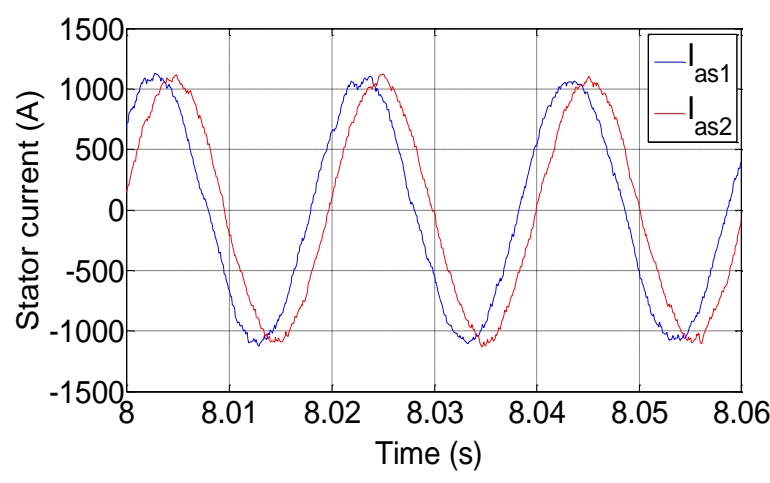

Figure 11.b Zoom of Stator current of the starl and star2

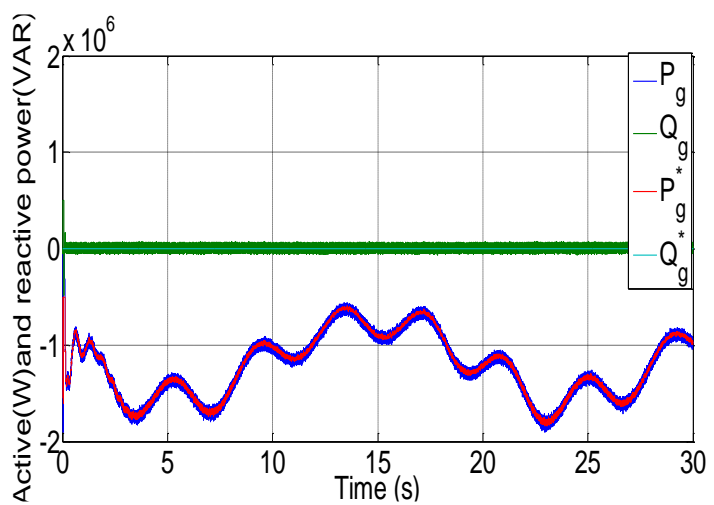

Figure 13. Grid active and reactive powers

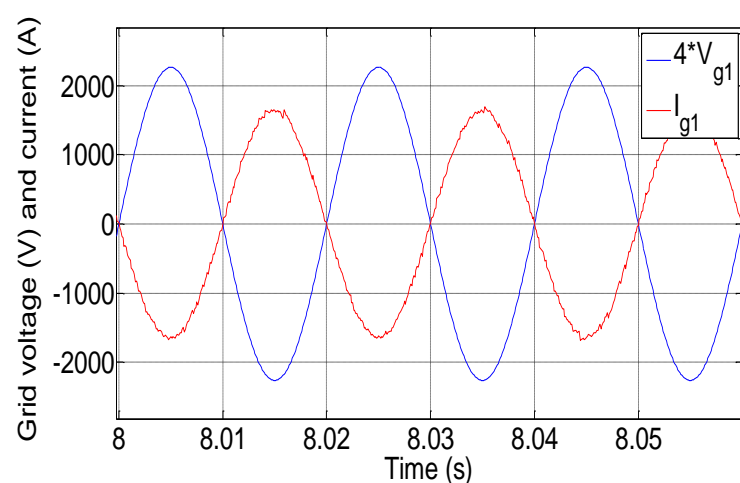

Figure 14.b. Zoom of the grid voltage and current 


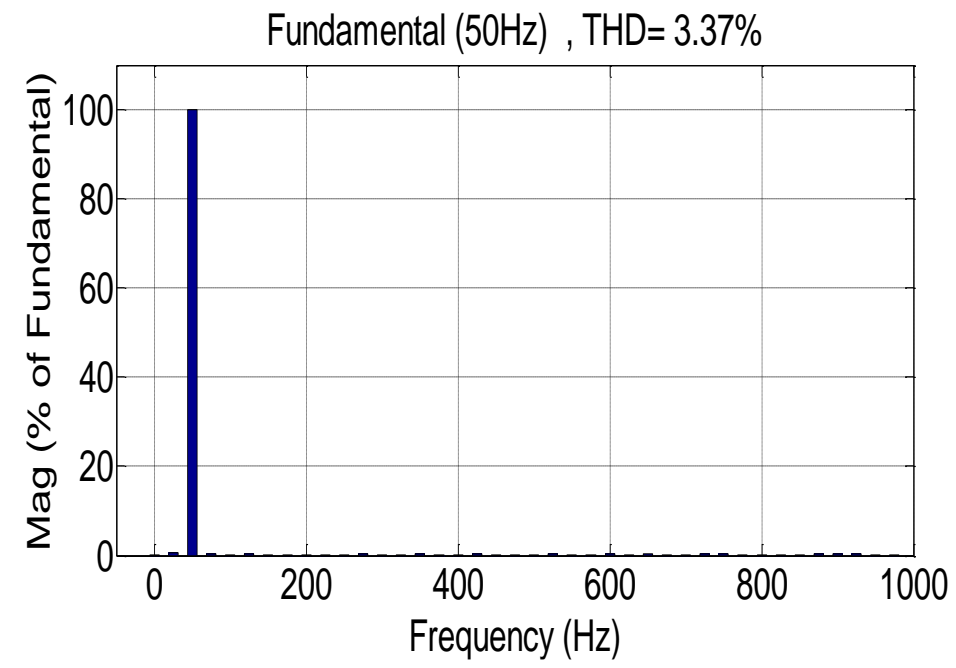

Figure 15. THD spectrum analysis of the grid current IgI for $\alpha=30^{\circ}$

Table 1. Effect of the angle position between the two stars on the THD of the generated current

\begin{tabular}{cccccc}
\hline $\boldsymbol{\alpha}\left({ }^{\circ}\right)$ & 0 & $\mathbf{1 0}$ & $\mathbf{2 0}$ & $\mathbf{3 0}$ & $\mathbf{4 0}$ \\
\hline $\mathrm{THD}(\%)$ & 4.49 & 3.81 & 3.41 & $\mathbf{3 . 3 7}$ & 3.81 \\
$\boldsymbol{\alpha}\left({ }^{\circ}\right)$ & $\mathbf{5 0}$ & $\mathbf{6 0}$ & $\mathbf{7 0}$ & $\mathbf{8 0}$ & $\mathbf{9 0}$ \\
$\mathrm{THD}(\%)$ & 3.53 & 3.66 & 3.55 & 3.97 & 3.54 \\
\hline
\end{tabular}

\section{CONCLUSION}

In this paper, we have investigated the modeling and the control of a system which converts wind energy into electrical energy. A variable speed control of wind turbines is studied in order to maximize energy extraction from the wind. A classical PI mode vector control for a DSIG drive is used in order to control the currents of the DSIG injected in the grid. It shows that good results are obtained. Indeed, the objective of the simulation study is to verify the influence of the displaced angle between the two stator windings of the DSIG on the grid generation current quality. The results show that at 30 degrees the Total Harmonic Distortion (THD) in the grid current is reduced compared to different displaced angles.

\section{Appendix parameters}

Turbine: Diameter $=72 \mathrm{~m}$, Number of blades $=3, \mathrm{G}=90, \mathrm{C}_{\mathrm{pmax}}=0.44, \lambda_{\mathrm{opt}}=7.05$.

DSIG: $P_{n}=1.5 \mathrm{MW}, \mathrm{U}=400 \mathrm{~V}, \mathrm{~F}=50 \mathrm{~Hz}, \mathrm{p}=2, \mathrm{R}_{\mathrm{s} 1}=\mathrm{R}_{\mathrm{s} 2}=0.008 \Omega, \mathrm{L}_{\mathrm{s} 1}=\mathrm{L}_{\mathrm{s} 2}=0.134 \mathrm{mH}, \mathrm{L}_{\mathrm{m}}=0.0045 \mathrm{H}, \mathrm{R}_{\mathrm{r}}=0.007$ $\Omega, \mathrm{L}_{\mathrm{r}}=0.067 \mathrm{mH}, \mathrm{J}=10 \mathrm{~kg} \cdot \mathrm{m}^{2}$ (turbine $\left.+\mathrm{DSIG}\right), \mathrm{f}=2.5 \mathrm{Nm} \mathrm{s} / \mathrm{rd}$ (turbine $+\mathrm{DSIG}$ ), $\mathrm{L}_{\mathrm{t}}=0.001 \mathrm{H}, \mathrm{R}_{\mathrm{r}}=0.01 \Omega, C=$ $0.072 \mathrm{~F}$.

\section{REFERENCES}

[1] H. Jabbari Asl, J. Yoon, "Power capture optimization of variable-speed wind turbines using an output feedback controller", Renewable Energy 86, p. 517-525, 2016.

[2] I. Villanueva, P. Ponce, A. Molina, "Interval Type 2 Fuzzy Logic Controller for Rotor Voltage of a Doubly-Fed Induction Generator and Pitch Angle of Wind Turbine Blades", IFAC-Papers 48(3), p. 2195-2202, 2015.

[3] B. Multon, O. Gergaud, H. Ben Ahmed, X. Roboam, S. Astier, B. Dakyo, C. Nikita, "L'électronique de puissance vecteur d'optimisation pour les énergies renouvelables", Ed. NOVELECT - ECRIN, ISBN : 2-912154-8-1, p. 97$154,2002$.

[4] F. Bu, W. Huang, Y. Hu, K. Shi, “An Excitation-Capacitor-Optimized Dual Stator-Winding Induction Generator with the Static Excitation Controller for Wind Power Application”, IEEE Transactions on Energy Conversion 26(1), p. 122-131, 2011.

[5] P. Daoutidis, M. Zachara, S.S Jogwarb, "Sustainability and process control: A survey and perspective", J. Process Control 44, p. 184-206, 2016.

[6] A.Boumassata, D. Kerdoun, N. Cherfia, N. Bennecib, "Performance of wind energy conversion systems using a cycloconverter to control a doubly fed induction generator", Energy Procedia 42, p.143-152, 2013.

[7] H. Amimeur, D. Aouzellag, R. Abdessemed, K. Ghedamsi, "Sliding mode control of a dual-stator induction forwind energy conversion systems", Electrical Power and Energy Systems 42, p. 60-70, 2012.

[8] S. Lekhchine, T. Bahi, Y. Soufi, "Indirect rotor field oriented control based on fuzzy logic controlleddouble star induction machine", Electrical Power and Energy Systems 57, p. 206-211, 2014. 
[9] S. Chekkal, N. Aouzellag Lahaçani, D. Aouzellag, K. Ghedamsi, "Fuzzy logic control strategy of wind generator based on the dual-stator induction generator", Electrical Power and Energy Systems 59, p.166-175, 2014.

[10] A. Tamaarat, A. Benakcha, "Performance of PI controller for control of active and reactive power in DFIG operating in a grid-connected variable speed wind energy conversion system", Front. Energy 8(3), P. 371-378, 2014.

[11] K. Bedoud, M. Ali-rachedi, T. Bahi, R. Lakel, "Adaptive Fuzzy Gain Scheduling of PI Controller for control of the Wind Energy Conversion Systems", Energy Procedia 74, p. 211 - 225, 2015.

[12] D. Kumar, K. Chatterjee, "A review of conventional and advanced MPPT algorithms for wind energy systems", Renewable and Sustainable Energy Reviews 55, p. 957-970, 2016.

[13] H. Labar, N. Zerzouri, M.S. Kelaiaia, "Wind turbine gearbox fault diagnosis based on symmetrical components and frequency domain”, Electr Eng. doi: 10.1007/s00202-015-03407.

[14] F. Hachicha, L. Krichen, "Rotor power control in doubly fed induction generator wind turbine under grid faults", Energy 44, p. 853-861, 2016.

[15] K. Ro, H. Choi, “Application of neural network controller for maximum power extraction of a grid-connected wind turbine system”, Electr Eng 88, p. 45-53, 2005.

[16] F. Ameur, K. Kouzi, "Genetic Algorithm Optimized PI and Fuzzy Logic peed Vector Control of Dual Stator Induction Generator in Wind Energy Conversion System”, Proceedings of the 3rd International Conference on Systems, Algiers, 29-31 Oct. 2013.

[17] S. Sünter, H. Altun, "Control of a permanent magnet synchronous motor fed by a direct AC-AC converter", Electr Eng 87, p. 83-92, 2005.

[18] Z. Tir, O.P. Malik, M. Eltamaly Ali, "Fuzzy logic based speed control of indirect field oriented controlled Double Star Induction Motors connected in parallel to a single six-phase inverter supply", Electric Power Systems Research 134, P. 126-133, 2016.

[19] S. El Aimani, "Modélisation de différentes technologies d'éoliennes intégrées dans un réseau de moyenne tension", Doctorate Thesis, France, L2EP Central School of Lille, 2004.

[20] Y. Errami, M. Ouassaid, M. Maaroufi, “Optimal Power Control Strategy of Maximizing Wind Energy Tracking and Different Operating Conditions for Permanent Magnet Synchronous Generator Wind Farm”, Energy Procedia 74, p. $477-490,2015$. 